\title{
"No le cambies a mi novela". Dominación y negociación entre géneros en el acto de ver televisión ${ }^{1}$
}

\author{
JuAn EnRiQue Huerta WonG*
}

Desde algunos estudios de audiencias de televisión se ha argumentado, al comparar los hábitos de recepción de hombres y mujeres, la dominación androcéntrica en el espacio doméstico. Pero otros estudios, de manera peculiar aquellos realizados en países emergentes como los latinoamericanos, parecen sugerir que puede haber prácticas de resistencia y/o alteridad a la dominación masculina doméstica, donde el control social doméstico existe en la medida en que es negociado, por tanto permitido, al interior de la unidad social doméstica, por el sujeto subordinado, es decir, el género femenino. Con base en 180 entrevistas realizadas en Monterrey, Guadalajara y el Distrito Federal, este trabajo explora la manera en que los receptores se relacionan con la televisión. Los hallazgos muestran que, en caso de existir dominación doméstica en el ritual de ver televisión, ésta no existe sin prácticas (tácticas) de alteridad en donde el género femenino no se construye siempre, por lo menos no de manera inconsciente, de manera subordinada.
From some television audiences studies has been argued, when comparing reception customs among men and women, andocentric domination within domestic space. But other studies, especially those done in emerging countries as the Latin Americans seem they're suggesting it could be resistance and/or choice practices to domestic male domination, where domestic social control exists as a negotiated issue, and therefore allowed by the subordinated subject, which means female genre. Based on 180 interviews applied in Monterrey, Guadalajara and Mexico City this work explores the ways of relationships between viewers and television. The findings shows that in case of an existing domestic domination while watching TV, this includes practices (tactics) of interchange where female genre not always is been constructed, or at least not unconsciously, in a subordinated way.

\footnotetext{
${ }^{\star}$ Tecnológico de Monterrey.

${ }^{1}$ Versiones preliminares de este trabajo se presentaron en el XI Encuentro Nacional de la Asociación Mexicana de Investigadores de la Comunicación y en la III Bienal Iberoamericana de Comunicación.
} 
La televisión ocupa un espacio importante en las sociedades contemporáneas. Según Lull (1988b), en muchas partes del mundo es uno de los factores que contribuyen a una tendencia de quedarse en casa. Agobiadas por la inseguridad, impotentes ante la inflación, las familias han preferido consumir la creciente oferta programática.

En México, 90\% de los hogares tienen por lo menos una televisión (Expansión 1997) y más de $80 \%$ de personas reportan verla a diario $(E l$ Norte 2001). El habitante promedio es un fuerte consumidor de televisión (heavy viewer), pues ve más de tres horas diarias (El Norte 2001), promedio internacional considerado como alto.

Si la cultura se objetiviza en sus productos y relaciones (González 1994), parece importante conocer cómo las audiencias otorgan sentido a su relación con la televisión. Es en este tipo de relaciones donde los juegos de fuerzas pueden verse (De Certeau 1996). Desde la perspectiva de los estudios de género, la relación de las audiencias y la televisión se ha abordado de diversas formas, apunta Lull (1988a). La más frecuente ha sido denunciar las estructuras de dominación androcéntrica, y cuyo mejor exponente es Morley (1992). De acuerdo con este autor, los hombres prefieren ver la televisión conociendo de antemano la programación; además, la ven atentamente y son capaces de relajarse mientras lo hacen. Esto se debe a que el hogar es un sitio para el tiempo libre y de descanso. También controlan los aspectos técnicos de la televisión, incluyendo el control remoto, el cual usan para cambiar de canal usando en ello su poder cultural. En cambio, las mujeres no influyen mucho en la selección, posesión y uso de aspectos técnicos. Ellas ven la televisión en forma distraída, porque manejan además sus responsabilidades domésticas mientras lo hacen, y son forzadas a construir otros tiempos para verla, por ejemplo, durante el día. El hogar es un sitio de trabajo para las mujeres, así que ellas nunca pueden relajarse y disfrutar a sus anchas ver la televisión, como los hombres.

Este tipo de generalizaciones cambia cuando los roles económicos lo hacen. Morley (1992) encontró que cuando las mujeres eran quienes proveían económicamente al hogar y los hombres estaban desempleados, los roles tendían a ser opuestos, del mismo modo que tendían a equilibrarse si las mujeres y los hombres trabajaban fuera de casa. Sin embargo, estas tendencias no alcanzaban a equilibrar los roles. La lectura de Morley es que el doméstico es un espacio de control y poder masculino, lo cual se ha convertido en un punto de partida, como ya Lull (1988b) lo ha dicho. 
Como también ha referido Lull (1988b), si de la evidencia en Europa y Estados Unidos se puede desprender que existe este tipo de dominación ( $c f$. Rogge y Jensen 1988), los datos procedentes de países emergentes $y$, en particular, de Latinoamérica, parecen permitir otro tipo de lecturas.

En Venezuela, las mujeres parecen ejercer el dominio pleno del televisor, sobre todo a la hora de la telenovela, como ha mostrado Barrios (1992). Hallazgos similares han sido encontrados en Chile (Fuenzalida 1992). En Colombia, Llano (1992) reporta que, incluso, las mujeres se muestran dominantes también al opinar frente al televisor. Su tipo de programa preferido, la telenovela, es objeto de conversación en todas partes. Los modos de ver televisión, variable que permite a Morley hablar de dominación, varía en algunos casos. Las mujeres venezolanas se instalan cómodamente frente al televisor mientras que las colombianas realizan siempre tareas domésticas, aun cuando no se encuentren en su hogar y vean sus programas favoritos en lugares públicos, reportan los datos.

En México, Covarrubias, Bautista y Uribe (1994) han encontrado que los miembros de la familia reconocen sus posiciones y establecen "una relación de sometimiento sutil ante las decisiones de quienes están a la cabeza del sistema de relaciones, que nunca son los hombres". En los casos en que el padre de familia ejerce el dominio aparente, existe una compleja red de tácticas ejercida, por ejemplo, por los hijos, que recurren a la madre como un frente de presión y negociación de lo que se ve en el televisor (también en González 1998).

En realidad, los datos no son tan diferentes. Como Lull (1988b) ha señalado, en la evidencia internacional del tema es posible hablar de "patrones característicos del involucramiento de las audiencias con la televisión [que] pueden ser considerados como rituales... [es decir] actividades familiares regulares, repetidas, elevadas casi a un nivel ceremonial debido al poder cultural de la televisión" (p. 238, cursivas en el original). De hecho, en su clásica compilación transnacional, encuentra que "los hombres donde quiera prefieren deportes, programas orientados a la acción y de información (especialmente noticias), mientras las mujeres prefieren dramas (series, telenovelas y películas) y programas basados en comedia, música y baile" (p. 248). Pero Lull advierte que el rigor de la observación de estos patrones se complementa con el análisis de la evidencia. Para él, las preferencias programáticas son extensiones de los roles familiares, por lo que en realidad, informarse es para el hombre 
parte de su responsabilidad. Un hombre fue acusado de volverse mitad mujer cuando reveló en su grupo de amigos que no le gustaba ver deportes, reporta.

En otros estudios, se ha encontrado que la supuesta dominación androcéntrica simplemente es una cuestión de preferencia por otro tipo de medios. En Colombia, las mujeres preferían oír la radio en su tiempo libre, pues asociaban la televisión con el trabajo, debido a que podían ver televisión mientras realizaban labores domésticas. De nuevo, las preferencias de consumo mediático reflejan extensiones del rol personal, pues las mujeres, en su preocupación por el mundo más cercano, preferían a la radio sobre la televisión, que con frecuencia se ocupa de temas y lugares más bien lejanos (Muñoz 1992). El mismo estudio encontró que la ficción, más recurrentemente la telenovela, ofrecía a las mujeres un modo de narración más pausado, el cual era preferido por su abundancia de detalles. De modo que otro supuesto para la dominación androcéntrica es que la televisión esté ofreciendo los formatos y tipos de mayor preferencia de las audiencias femeninas, es decir, que estén interesadas en ver televisión y mantengan desventajas en la toma de decisiones de qué y cómo se exponen a sus mensajes.

Este trabajo pretende ofrecer un poco más de información respecto a cómo los géneros participan de la toma de decisiones de qué se ve en televisión, reportando hallazgos de la oferta disponible en la televisión abierta mexicana, las preferencias programáticas de hombres y mujeres de México, su participación en la selección de los programas que ven, sus modos de ver y su dominio del control remoto. Se presentan al inicio datos de un diagnóstico de la oferta informativa en los cuatro canales nacionales abiertos y, después, se ofrece un análisis cuantitativo y cualitativo del consumo televisivo por parte de hombres y mujeres de las áreas metropolitanas de las ciudades de México, Guadalajara y Monterrey.

Las preguntas de investigación planteadas para este trabajo son las siguientes:

Oferta:

1) ¿Cuál es la oferta de formatos televisivos en toda la programación y en horario AAA?

Consumo:

2) ¿Cuáles son las preferencias programáticas de hombres y mujeres?

3) ¿Hay alguna diferencia en la frecuencia y la forma en que hombres y mujeres reportan decidir los programas que verán?

4) ¿Cómo reportan hombres y mujeres el poder de decisión y la negociación sobre qué y cómo se ve televisión? 


\section{MÉTODO}

Los datos utilizados en este trabajo provienen de los proyectos realizados en el programa de investigación Televisión y Vida Cotidiana, establecido en el Tecnológico de Monterrey en 1999 con el auspicio de la Cátedra Televisa. El programa es dirigido por José Carlos Lozano Rendón.

\section{Oferta}

Para obtener datos de la oferta se efectuó un análisis de contenido de fuentes secundarias. Para ello, se usó una muestra compuesta por cuatro semanas de programación (febrero 8-14, mayo 10-16, agosto 9-15 y noviembre 8-14). Se seleccionó la segunda semana del segundo mes de cada trimestre. Se dividió el periodo de análisis (un año) en cuatro partes, y se escogieron las semanas justo enmedio de cada trimestre, con el fin de eliminar sesgos. El primer instrumento de trabajo fue la página de cartelera del periódico Excélsior ${ }^{2}$ de donde se codificó la información. No se realizó una segunda muestra, sino que se censaron todas las semanas, codificando toda la programación de los canales abiertos nacionales; a saber, 2 y 5 de Televisa y 7 y 13 de tv Azteca. Se aplicaron pruebas piloto y de confiabilidad a la programación de una semana (abril 12-18), contando con un manual y hoja de codificación de variables semiabiertas, tras lo cual se despejaron dudas acerca de los tipos programáticos y se cerraron las variables hasta hacerlas nominales, para integrar un manual y hoja de codificación finales.

La unidad de análisis fue el programa y, para fines operacionales, se codificó el número de minutos que cada uno registró ( $n=118925)$, de modo que el análisis está hecho a partir de los minutos de programación y no del número de programas que forman la muestra.

\section{Consumo}

Se reportan aquí datos cuantitativos y cualitativos sobre el consumo. Aunque fueron levantados en tres ciudades, este trabajo no establece comparativos por ciudad sino datos globales (para un contraste de los datos cuantitativos por ciudad, confróntese con Huerta Wong y Cerda Cristerna 2001).

\footnotetext{
${ }^{2}$ Para una explicación detallada de por qué se tomaron las decisiones en la metodología, véase Huerta Wong 2000.
} 
Los datos cuantitativos sobre el consumo de noticieros provienen de 2,676 entrevistas por muestreo aplicadas casa por casa en población mayor de 18 años de edad en las áreas metropolitanas de Monterrey, Guadalajara, y el Distrito Federal, durante los meses de marzo y abril de 1999. El tamaño de la muestra para cada ciudad (mínimo 800 casos) permite la comparación por sexo y nivel socioeconómico. ${ }^{3}$

Los datos cualitativos fueron resultado de 180 entrevistas realizadas en las tres ciudades de mayo a septiembre de 1999 (60 en cada población), con el objetivo de explorar y comprender los procesos de integración de la televisión en la vida cotidiana de diferentes grupos de la audiencia. Se utilizó la "entrevista con informantes" (Lindlof 1995), es decir, se redactó un cuestionario fijo que permitió cubrir las áreas teóricamente prioritarias con cada informante. Según Lindlof, este tipo de entrevista proporciona un contenido de alto grado comparativo entre los diferentes entrevistados y muestras relativamente grandes de los mismos. Los entrevistadores ${ }^{4}$ pudieron agregar y explorar temas adicionales y aceptar que el informante abordara otros aspectos de su experiencia televisiva no incluidos en el cuestionario (lo que de hecho fue muy recomendado para enriquecer el trabajo de campo), pero no omitieron ninguna de las preguntas incluidas en el mismo.

Se definió que en cada ciudad debían aplicarse un mínimo de 60 entrevistas, y que ese número debería aumentar en caso de que se observaran diferencias importantes en las respuestas proporcionadas por los informantes de cada segmento. Esto no fue necesario, pues al hacer una valoración de la evidencia (20 entrevistas para cada nivel socioeconómico, 10 hombres y 10 mujeres para cada uno de estos niveles), se consideró que había coincidencias constantes.

\section{Resultados}

\section{Oferta}

La Tabla 1 muestra que la oferta de formatos televisivos que las mujeres han preferido en la evidencia internacional del tema, es mayor a la de

\footnotetext{
${ }^{3}$ Para una explicación de los detalles de la muestra, tales como los valores $z, p, q$ y $e$, véase Huerta Wong y Cerda Cristerna 2001.

${ }^{4}$ Además del equipo de coordinadores de la investigación en Monterrey, profesores de los campus Estado de México y Guadalajara fungieron como entrevistadores en el levantamiento de datos cualitativos.
} 


\section{TABLA 1}

OFERTA DE FORMATOS TELEVISIVOS SEGÚN HORARIO

Horario

Total

\begin{tabular}{cccccccc}
$\mathrm{A}$ & $\%$ & $\mathrm{AA}$ & $\%$ & $\mathrm{AAA}$ & $\%$ & & $\%$ \\
\hline $\begin{array}{c}\text { Información } \\
20,010\end{array}$ & 33.9 & 1,440 & 5.6 & 3,585 & 10.5 & 25,035 & 21.1 \\
$\begin{array}{c}\text { Ficción } \\
6,825\end{array}$ & 11.6 & 9,655 & 37.4 & 17,665 & 51.9 & 34,145 & 28.7 \\
$\begin{array}{c}\text { Infoshow } \\
1,050\end{array}$ & 1.8 & 1,650 & 6.4 & 2,325 & 6.8 & 5,025 & 4.2
\end{tabular}

Variedades y entretenimiento

$\begin{array}{rlllllll}3,095 & 5.2 & 2,310 & 8.9 & 4,560 & 13.4 & 9,965 & 8.4 \\ \begin{array}{c}\text { Infantiles } \\ 18,180\end{array} & 30.8 & 8,560 & 33.1 & 2,850 & 8.4 & 29,590 & 24.9 \\ \begin{array}{c}\text { Deportes } \\ 4,405\end{array} & 7.5 & 2,120 & 8.2 & 2,330 & 6.8 & 8,855 & 7.4\end{array}$

Culturales

$\begin{array}{llllllll}420 & 0.7 & 90 & 0.3 & 600 & 1.8 & 1,110 & 0.9\end{array}$

Educativos

180

0.3

$\begin{array}{ll}180 & 0.2\end{array}$

Telemercadeo

$\begin{array}{lrrr}4,890 & 8.3 & 4,890 & 4.1\end{array}$

Propaganda política

$\begin{array}{llllllll}30 & 0.1 & 30 & 0.1 & 100 & 0.3 & 130 & 0.1\end{array}$

Total

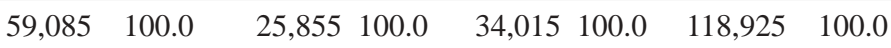

Fuente: Huerta Wong, J. E. (2000) Hacia una evaluación de la televisión mexicana:

Diversidad en la programación abierta durante 1999, tesis de maestría, Tecnológico de Monterrey, Monterrey, Nuevo León.

aquellos formatos que los hombres han preferido. La suma de formatos como ficción y variedades/entretenimiento es mucho mayor a la de formatos como información y deportes.

Esta diferencia es mayor aún en el horario AAA, donde la diferencia entre ficción e información, para citar los casos de los formatos mencionados con más frecuencia por mujeres y hombres, respectivamente, como preferidos, es de cinco a uno. Estos datos sugieren que existe, por lo menos a grandes rasgos, una oferta que podría ser más del agrado del público femenino, lo cual es importante, pues para ver los hombres sus programas favoritos, tendrían que ejercer una mayor presión, o también 
porque ello podría dar lugar a concesiones de parte del público femenino, al conocer que es mayor la oferta destinada a sus preferencias.

\section{Exposición y consumo}

Como se ha explicado, un punto de partida para la dominación y/o negociación frente al televisor es que existen patrones de preferencias televisivas en la evidencia internacional sobre el tema (Lull 1988b). Sin el interés mutuo por un objeto en común, carece de sentido el desenlace de fuerzas y relaciones que hacia el interior del espacio doméstico sostienen los géneros. ¿Cuáles son las preferencias programáticas de hombres y mujeres en Guadalajara, México y Monterrey? Es una pregunta que, en principio, tiene que ver con la correspondencia con la oferta. Como se han presentado datos de formatos televisivos y no de tipos, la comparación resulta un poco difícil, pero se intenta aquí.

Lo primero que salta a la vista en la Tabla 2, es que los principales tipos de los formatos televisivos ficción e información difieren de los antecedentes recabados en otros países. Como se puede apreciar, los noticieros aparecen como el tipo más visto tanto por hombres como por mujeres. Esto también se aleja de la evidencia internacional en el sentido de que no es la ficción el formato más visto, y también se aleja de la programación, lo que de entrada abriría preguntas acerca de la correspondencia entre la oferta de la carta programática mexicana y las audiencias. Morley (1992), en cambio, señala que la diferencia radica en que las mujeres ven noticieros locales y los hombres internacionales, y Lull (1988b) ha insistido en que aquí entran en juego extensiones de roles personales, donde las mujeres se preocupan por el entorno de lo doméstico y los hombres por la economía y la política, en su rol de proveedores. Lozano y Martínez (2000) no sólo coinciden con la falta de diferencias en la preferencia de los noticieros, sino que encuentran que hombres y mujeres parecen ser igualmente críticos al exponerse a este tipo de mensajes.

Como ya también ha anotado Cerda Cristerna (1999), los resultados de la Tabla 2 también se alejan de los hallazgos de Covarrubias, Bautista y Uribe (1994), para quienes la telenovela era un tipo preferido por ambos géneros. De hecho, es el tipo en que más diferencias presenta, pues la respuesta masculina se acerca más a "Rara vez", en tanto que la femenina se acerca más a "Frecuentemente". Las mujeres se exponen 


\section{TABLA 2}

\section{EXPOSICIÓN A TIPOS TELEVISIVOS SEGÚN GÉNERO}

Género $\quad N \quad x^{*} \quad s \quad t \quad$ Significancia

Noticieros

$\begin{array}{lrrrrr}\mathrm{F} & 1,791 & 1.68 & 1.07 & 0.506 & 0.613 \\ \mathrm{M} & 860 & 1.66 & 0.98 & & \end{array}$

Telenovela

$\begin{array}{lccccc}\mathrm{F} & 1,782 & 2.30 & 1.57 & -21,783 & 0.001 \\ \mathrm{M} & 857 & 3.72 & 1.54 & & \end{array}$

Concursos

$\begin{array}{lrrrrr}\mathrm{F} & 1,771 & 3.09 & 1.53 & -3,633 & 0.001 \\ \mathrm{M} & 852 & 3.32 & 1.45 & & \end{array}$

Aventuras

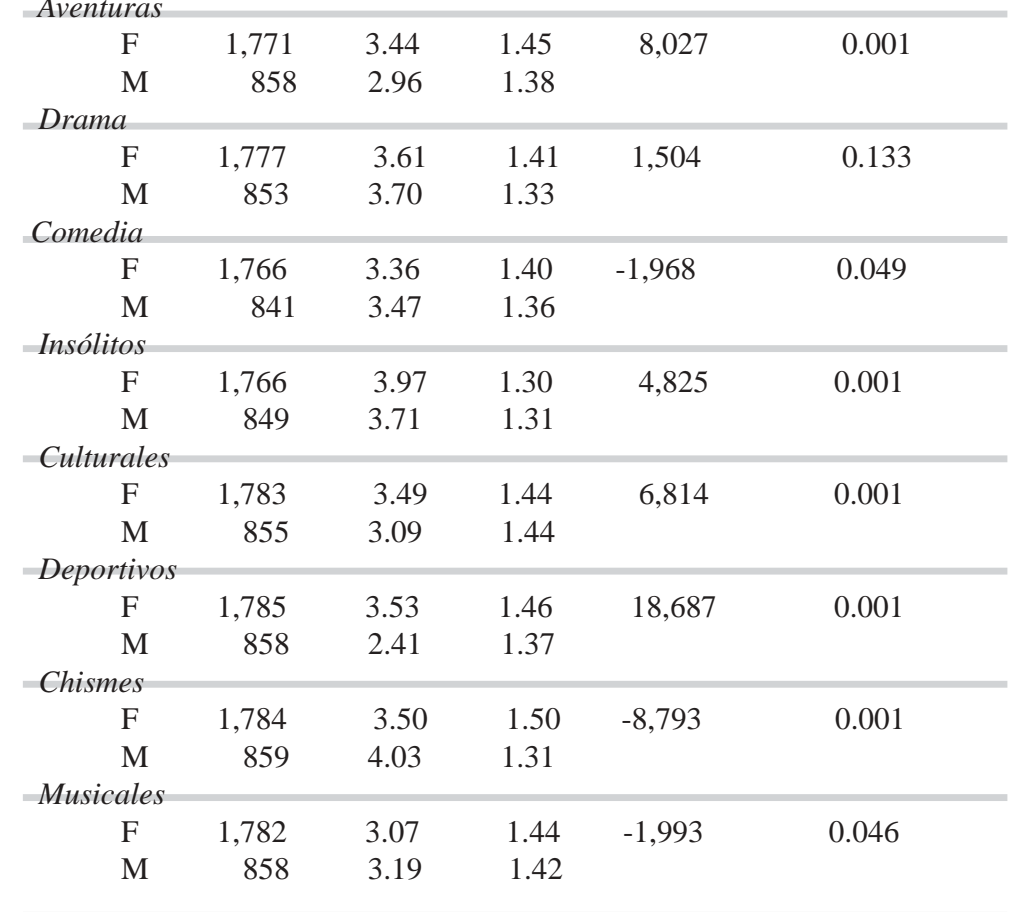

*Media en la escala: 1=Muy frecuentemente, 2=Frecuentemente, 3=Regularmente, 4=Rara vez, 5=Muy rara vez. 
más a programas de concursos, comedia, chismes y musicales, mientras que los hombres prefieren programas de aventuras, insólitos y deportivos. En líneas generales, esto parece coincidir con los patrones de exposición a la televisión, pero surge otra pregunta acerca de la falta de diferencias significativas en el drama, otro de los tipos clave de la ficción. Lo que podemos aprender de las tablas 1 y 2 , en resumen, es que los géneros parecen tener respuestas similares a la oferta programática, si bien ésta no parece del todo satisfactoria a sus preferencias.

De acuerdo con Morley, una de las diferencias que indica el dominio masculino en el hogar es la forma en que ambos géneros programan lo que verán. Para usar su tiempo libre a sus anchas, el hombre programa consultando la cartelera, o bien, está acostumbrado a sus programas favoritos y logra verlos con mayor frecuencia que las mujeres. Como muestra la Tabla 3, los resultados coinciden parcialmente con este supuesto. Los hombres consultan más la cartelera que las mujeres, aunque en ninguno de los casos es frecuente este tipo de toma de decisiones. Asimismo, las mujeres reportan, en mayor número de ocasiones que los hombres, terminar viendo algo que otra persona sintonizó. Si bien son estadísticamente válidas estas diferencias, en ninguno de los dos casos son notorias las frecuencias de menciones, y son más bien pequeñas en el segundo caso. Por otro lado, la Tabla 3 también muestra que las mujeres conocen con mayor frecuencia los horarios de sus programas favoritos y los sintonizan sin ningún problema. De acuerdo con los hallazgos de estudios hechos en Chile, Venezuela y Colombia, esto puede empatizar con las preferencias por las telenovelas y su marcada afición a sintonizarlas, como se ha visto en la Tabla 2.

La Tabla 4 ahonda en los datos acerca de la frecuencia con que hombres y mujeres toman decisiones acerca de qué ven. A la pregunta de "¿Con qué frecuencia otra persona selecciona los programas que usted ve?", la respuesta en general es "A veces", aunque sí hay una diferencia estadística según la cual, parece ser algo más raro en el público masculino que en el femenino que otra persona decida sobre los programas que se ven. No ocurre así en el caso de la pregunta "¿Con qué frecuencia ve un programa que no tenía planeado originalmente?", donde hombres y mujeres reportan que "A veces", sin diferencias estadísticas significativas. En cualquier caso, no es claro que exista una diferencia clara en la toma de decisiones que sobre ver la televisión ejercen los géneros, lo que contradice los hallazgos de Morley y está más en sintonía con los resultados de investigaciones efectuadas en Latinoamérica. 
TABLA 3

FORMA EN QUE LOS GÉNEROS DECIDEN LO QUE VEN

Forma de decidir lo que ve Femenino \% Masculino \% Total \%

$\begin{array}{lllllll}\text { Consulto la cartelera del } & 99 & 5.5 & 94 & 10.9 & 193 & 7.3\end{array}$ periódico o Teleguía.

Conozco horario de mis

$\begin{array}{llllll}913 & 51.1 & 355 & 41.3 & 1268 & 47.9\end{array}$

programas favoritos y los

sintonizo de acuerdo a la hora.

No tengo plan: enciendo, veo

y me detengo en algún

$\begin{array}{llllll}638 & 35.7 & 358 & 41.6 & 996 & 37.6\end{array}$

programa que me llama la atención.

Veo lo que otros decidieron sintonizar.

Varias de las opciones.

$\begin{array}{llllll}57 & 3.2 & 10 & 1.2 & 67 & 2.5\end{array}$

$\begin{array}{llllll}81 & 4.5 & 43 & 5 & 124 & 4.7\end{array}$

Total

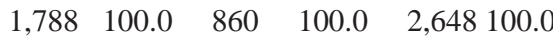

$\mathrm{p}=0.001$

En resumen, los datos cuantitativos no parecen dar mayor soporte al supuesto de la hegemonía masculina al interior del espacio doméstico. Dadas sus limitaciones, es necesario intentar explicar los complejos procesos mediante los cuales las audiencias se relacionan con la televisión y ponen de manifiesto así su sistema de fuerzas (Gonzalez 1994). Para ello, las entrevistas resultan muy valiosas para introducirnos en quién y cómo se toman las decisiones acerca de qué se ve en televisión.

En la superficie, parece haber una clara hegemonía masculina del modo que lo ha referido Morley (1992). Esta hegemonía se representa cuando el hombre decide qué ver, incluso si llega una vez que la televisión se ha encendido y alguien la está observando, y usa el control remoto como símbolo de ese poder. Además, se instala cómodamente frente al televisor mientras su compañera continúa trabajando en el hogar. Guadalupe, una mujer de nivel socioeconómico alto, expresó:

Yo la selecciono más bien cuando yo estoy casi siempre sola. Cuando estoy con mi esposo casi siempre es él quien la selecciona porque además, te digo, yo me muevo mucho, aun cuando estamos dizque viendo la televisión, pues yo me paro o por algo, o estoy acomodando ropa o estoy haciendo algo, entonces, el que sí suele cambiarle es él más que yo. 
Incluso cuando hay un primogénito varón, la mujer parece no existir. Como reporta Alfredo, un joven de nivel socioeconómico alto:

Bueno, en mi cuarto el que manda en la tele soy yo. Fuera de mi cuarto, en el cuarto de mi papá, manda mi papá y en la tele pues también mi papá es el que se encarga. Yo creo que si ponemos la tele en la tienda como un lugar neutro en el que se puede decidir quien le cambia de canal, yo creo que mi papá tiene un 75 por ciento del control y yo un 25 en todo el día.

Como también refiere Lull (1988a) al hablar de las preocupaciones del enfoque marxista en este tipo de estudios, algunos informantes llegan a reportar la reproducción de la estructura jerárquica tradicional en el acto de ver televisión. Olivia, una mujer de nivel socioeconómico alto, señaló:

Cuando está mi marido, lo dejo como que fuera él el dueño de la televisión. Entonces me pongo a ver lo que él escogió. Cuando estoy yo sola, yo marco, o sea, aunque llegue cualquiera de los muchachos, o sea, yo digo, pues no me la mueves porque estoy viendo este programa y ahí me lo dejas.

Pero en el ejercicio del poder, se entretejen tácticas de resistencia, como afirma De Certeau (1996) y como bien ha documentado Llano (1992). Patricia, una mujer de cuarenta años y nivel socioeconómico bajo, reveló:

Él [decide lo que se ve en televisión], porque como es un rato nada más que ve la televisión, entonces ya, y yo me ocupo de otras cosas, como le digo yo estoy haciendo de cenar pero desde allí estoy viendo cuando era la novela ésta la de Esperanza se llamaba la muchacha, no me puedo acordar el nombre, eh, en esta novela le decía "no le cambies porque desde aquí la estoy viendo" como... este... donde yo vivo son los cuartos seguidos, entonces desde la cocina a la sala se alcanza a ver bien la tele y a escucharla, porque no es muy grande mi casa, entonces este, en los comerciales le cambiaba "¿ya le cambiaste nuevamente?” y allí echaba pleito yo con él porque "no le cambies que desde acá la estoy viendo yo, tú crees que no la veo pero desde acá la estoy viendo yo, desde acá, no me la cambies" [risas], pero, este, no, casi por lo regular en la noche él es el poder absoluto en la tele".

La declaración de Patricia hace pensar que concede la televisión porque el rol que de ella se espera es que actúe así en consideración al 


\section{TABLA 4}

FRECUENCIA CON LA QUE LOS GÉNEROS DECIDEN LO QUE VEN

Género $\quad N \quad x^{*} \quad s \quad t \quad$ Significancia

Otro selecciona los programas que usted ve

$\begin{array}{lrrrrr}\mathrm{F} & 1,721 & 3.16 & 1.25 & -3.773 & 0.001 \\ \mathrm{M} & 822 & 3.36 & 1.18 & & \end{array}$

Ve un programa no planeado originalmente

$\begin{array}{lrrrrr}\mathrm{F} & 1,767 & 3.38 & 1.07 & 0.813 & 0.416 \\ \mathrm{M} & 854 & 3.35 & 1.09 & & \end{array}$

*Media en la escala: 1=Muy frecuentemente, 2=Frecuentemente, 3=Regularmente, 4=Rara vez, 5=Muy rara vez.

escaso tiempo que su esposo pasa frente a la televisión. Sin embargo, parece difícil pensar en que su forma dominante y real de proceder no sea un hecho rutinario. Como ya se ha dicho, las mujeres de Colombia (Llano 1992) parecían tener una actitud semejante.

Los hombres parecen colaborar en esos casos. Como relata Ricardo, un hombre de cuarenta años y nivel socioeconómico medio: "Si a mí no me gusta y ella dice no, voy a ver la novela, bueno, ve la novela y yo me retiro, no veo televisión".

A lo largo de las entrevistas se registran datos encontrados acerca del control de la televisión. Las menciones acerca del control femenino no son menores. Laura, una mujer regiomontana de nivel socioeconómico medio, expresó:

Por lo regular soy yo [la que selecciona lo que se ve en televisión]. Esporádicamente, cuando agarra el control Rubén, es él [se ríe], pero tratando siempre de ver algo que nos guste a los dos.

¿Qué tan esporádicamente, qué porcentaje dirías?

Pues yo un 90 y él, 10.

Algunos informantes parecían tener relaciones de fuerza frente al televisor, exactamente al revés de lo que Morley encontró en Inglaterra. Es el caso de Ricardo, un regiomontano de nivel socioeconómico medio:

A mí me gusta dejarla, o sea, verla, no estarle cambiando y mi señora busca otro programa, no, acá está, quiere ver tres o cuatro programas a la vez, en los comerciales vámonos al otro, a veces yo también lo hago, verdad, pero realmente me gusta ver una sola cosa y ella sí es muy dada a eso, 
a que ve la novela, ve la película y está viendo las noticias y está con el control en la mano...

Entonces, aunque usted tenga el control, ella tiene el control.

Sí, ella tiene el control, y ella dice préstamelo y yo se lo vuelvo a quitar y préstamelo, o sea lo tengo yo así, pero ella es realmente la que lo mueve, yo lo tomo nada más para bajarle al volumen...

Pero en la mayoría de los casos parece haber una tendencia a regular la hegemonía, a establecer políticas que pueden ser o no explícitas. Si bien en algunos casos estas políticas contribuyen a reproducir la estructura de poder tradicional, en gran parte parecen producto de negociaciones destinadas a garantizar la conformidad de todos los miembros de la familia, incluso su bienestar, como son ciertas prohibiciones que tienen que ver con horarios no aptos para niños o programas que parecen contrarios a la forma en que los padres de familia quieren educar a sus hijos.

Ana, una joven tapatía de nivel socioeconómico medio, lo traduce como "respeto":

Hay un respeto, de que saben que a mí me gusta en este caso La Nana, Los Simpson, o el programa que veo los sábados en el Canal 22, entonces saben que ahí, yo a esa hora quiero ver ese programa, ya no es tanto de oigan me permiten, voy a ver esto... ya cuando hay gente externa en la casa, que no conocen las reglas, pues ya hay un poco más de flexibilidad en ese aspecto...

O sea, pero sí hay como una regla...

Sí hay, mm de que, ya sabemos que a Xóchitl [su hermana] le gusta ver MTV a esta [hora] pues si no vamos a moverla...

Angelina, una regiomontana de nivel socioeconómico bajo, refiere actuar como vigilante del cumplimiento de las políticas domésticas:

Cuando está mi esposo hay muchos programas que a mí no me gusta que vea, por ejemplo Picardía mexicana, pero yo no lo dejo ver porque están los niños, porque sale mucha inmoralidad y yo le digo esos programas no me gustan para los niños, ellos deben de vivir su juventud, su niñez y eso ya los está pasando a otra etapa.

Estas políticas se han establecido mediante la negociación, consciente o no, y atiende a criterios más o menos lógicos respecto al derecho de cada género a ver televisión. Así lo sugiere Rosa, una regiomontana de nivel socioeconómico medio: 
Pues como yo estoy más tiempo en la casa, pues en el día yo le cambio y en la noche como él quiere ver, pues él selecciona lo que quiere ver y no le presto casi atención, entonces lo que yo quiero ver yo lo programo o yo le cambio y [al revés].

Salvador, un joven de nivel socioeconómico medio, agrega:

Mi mamá se pone generalmente a ver televisión en las tardes en la que está en la sala, y pues siempre que llego temprano ella está viendo sus novelas o algún programa y nadie le cambia, ya después de cierta hora y ya saben qué es lo que va a ver o qué es lo que sigue, o sea, se hacen ciertas costumbres, por ejemplo, ya que se acaba la novela y a las ocho empieza mi programa ya le cambio y todos lo ven y a las nueve "no que oigan es que van a pasar un especial de no sé qué...” es que le cambian y pues ya lo vemos todos.

Esas negociaciones incluyen también factores como las extensiones técnicas del televisor, es decir, el control remoto, el uso de la videocasetera o de los televisores equipados con televisión privada satelital de alto costo (Sky, frecuentemente). Arturo, de nivel socioeconómico alto, refiere: "No hay pleito con el control, nos turnamos".

Socorro, tapatía de nivel socioeconómico alto, agrega:

La tele de la sala de arriba que tiene el decodificador, esa tele es para ver películas con el decodificador, no dejamos que Arturo se ponga a ver la novela del dos si la puede ver en las otras teles... entonces así es como lo negociamos... ya están las reglas muy implícitas en esta casa, todo mundo se las sabe.

Y Alfredo, de nivel socioeconómico alto, coincide, y añade un rasgo interesante, que también fue frecuente: entre hermanos, muchas veces es la mujer la que mantiene la hegemonía al interior del espacio doméstico.

Si mis hermanos están viendo la tele pues te aguantas o si quieres ver tú la tele pues te vas a la tele de tu cuarto pero ahí no tienes Sky... [si no nos ponemos de acuerdo] generalmente sería mi hermana la que escogería, inclusive tiene más poder que mi hermano. 


\section{DisCUSIÓN}

¿Cuál es la oferta de formatos televisivos en toda la programación y en horario AAA? ¿Cuáles son las preferencias programáticas de hombres y mujeres? ¿Hay alguna diferencia en la frecuencia y en la forma en que hombres y mujeres reportan decidir los programas que verán? ¿Cómo reportan hombres y mujeres el poder de decisión y la negociación sobre qué y cómo se ve televisión?

Las preguntas anteriores han motivado este texto, cuyo objetivo ha sido contribuir a lo que se sabe acerca de la forma en que hombres y mujeres se relacionan con la televisión y hacen objetivo su sistema de fuerzas en esta relación. Un supuesto de partida ha sido el principio de que es posible obtener patrones generales de este tipo de relaciones, debido a que las audiencias establecen formas ritualizadas en el acto de ver televisión (Lull 1988b).

La oferta televisiva de México parece inclinarse hacia lo que en la evidencia internacional del tema aparece como preferencias femeninas, particularmente en los horarios de mayor audiencia. Esto, sin embargo, parece corresponder sólo parcialmente a las preferencias de los públicos mexicanos, que se muestran muy inclinados a ver noticieros. Las mujeres de la muestra reportaron con mayor frecuencia que los hombres conocer el horario de sus programas favoritos y sintonizarlos en el momento, lo cual constituyó la diferencia más importante de la forma en cómo los géneros reportan decidir lo que ven. Esto parece estar en consonancia con la forma en cómo las mujeres de Venezuela (Barrios 1992), Colombia (Llano 1992) y Chile (Fuenzalida 1992) mostraban su hegemonía al momento, por ejemplo, de sentarse a ver telenovelas.

Pero las mujeres de la muestra también reportaron más frecuentemente ver programas que otra persona selecciona. Los hombres reportaron con más frecuencia consultar la cartelera para seleccionar los programas que veían y, en menos ocasiones, ver programas que otras personas decidieron sintonizar. Esto podría sugerir, sin embargo, que los hombres deciden menos frecuentemente que las mujeres qué ver, para lo cual tienen que informarse, razón por la cual también establecen un doble ritual del acto de ver televisión, el cual empezaría desde su selección. En cualquier caso, las diferencias entre ambos géneros respecto a la frecuencia y forma en que hombres y mujeres reportaron decidir los programas que ven, no es muy grande, aunque quizá convenga revisar las pequeñas diferencias anotadas aquí, en análisis posteriores. 
Mayor atención merecen los hallazgos respecto a cómo hombres y mujeres parecen negociar la forma en que se decide la exposición a la televisión, instalando frecuentemente políticas del cuarto de ver televisión, para usar un término muy utilizado en los estudios culturalistas (Orozco 1992). Estas políticas pueden variar sus grados de rigidez e institucionalización, pero a menudo parecen producto de negociación debida a motivos como el respeto a los derechos de todos los miembros de la familia, o la vigilancia de la forma en cómo los padres consideran que los niños deben ser educados.

Entre los hallazgos que dan pie a esta discusión, resultan importantes de subrayar aquellos que incluyen la institucionalización de las políticas sobre el uso de las extensiones técnicas de la televisión, tales como el control remoto o la televisión satelital. Como ya ha anotado Lull (1988b), su uso restringido, tanto en capacidad como en las habilidades que demandan, podría abrir nuevas formas de relaciones entre los géneros. Los datos que aquí se reportan parecen permitir cierto optimismo respecto a la horizontalización de este tipo de herramientas en particular, y de la relación entre los géneros frente al televisor.

Existen, sin embargo, algunos puntos que precisar respecto a los hallazgos. Las generalizaciones que de aquí derivan han de tomarse con precaución, pues la cantidad de variables analizadas no permiten declaraciones rotundas sobre quién ostenta el dominio al interior del espacio doméstico. No han sido, por ejemplo, presentados los datos acerca del tipo de actividades o del contenido de medios al que están expuestas las audiencias mientras ven televisión, algo que los estudios culturalistas han referido como de suma importancia para entender cómo se realizan los procesos de recepción y cómo las audiencias toman sentido de su relación con la televisión y la incorporan a su vida cotidiana. Otro factor delimitante es que el análisis no ha tomado en cuenta otro tipo de variables como el nivel socioeconómico o la composición demográfica/económica de las familias, que permitiría mayor precisión (accuracy). Del mismo modo, aunque hay algunos rasgos que sugieren que el papel que desempeñan hombres y mujeres al interior del hogar es fundamental en la toma de decisiones de exposición a la televisión, la escasez de los datos mostrados no hace posible crear una discusión respecto, por ejemplo, de si los hijos varones tendrían un ascendente sobre la madre, aunque Yarto (1999) ha encontrado que las hijas/hermanas son de hecho muy dominantes con padres o hermanos. Más análisis tendrán que ser efectuados en estos sentidos. 
Por otra parte, ¿qué significa que las mujeres urbanas posean gran parte del poder de toma de decisiones en la relación entre las familias urbanas y la televisión? En principio no significa más que ello, y el espacio no permite teorizar con mayor profundidad. Baste decir por ahora que ello no implica dejar de preocuparse por una sociedad que, en la cotidianidad simple, aparece como profundamente machista, como podrá saberlo cualquier mujer que se anime a caminar sola por cualquiera de las tres ciudades en el estudio. Pero quizá podría ser diferente y quizá podemos ser algo optimistas respecto al futuro de las relaciones de género, si el espacio doméstico, como han sugerido desde siempre las feministas, es en realidad el principio del espacio público, y si la relación de los medios de comunicación y sus públicos, como también han sugerido siempre los culturalistas ( $c f$. Thompson 1998) es el escenario de la esfera pública.

\section{REFERENCIAS BIBLIOGRÁFICAS}

BARrios, L. (1992) “Televisión, comunicación y aprendizaje en el contexto de la familia: estudio etnográfico realizado en Venezuela”, en G. Orozco (comp.), Hablan los televidentes: estudios de recepción en varios países, Cuadernos de Comunicación y Prácticas Sociales, núm. 4. México: Universidad Iberoamericana, Programa Institucional de Investigación en Comunicación y Prácticas Sociales, pp. 55-74.

Cerda Cristerna, A. (1999) Maneras de ver y usar la televisión: Análisis por género y nivel socioeconómico de los hábitos de consumo televisivo de las audiencias de Monterrey, México y Guadalajara, tesis de maestría, Tecnológico de Monterrey.

Covarrubias Cuéllar, K., A. Bautista, y B. A. Uribe (1994) Cuéntame en qué se quedó: La telenovela como fenómeno social. México: Trillas.

De Certeau, Michel (1996) La invención de lo cotidiano: Artes de hacer, (1). México: Instituto Tecnológico y de Estudios Superiores de Occidente/Universidad Iberoamericana/Centro Francés de Estudios Mexicanos y Centroamericanos.

Expansión (1997) “¿Anunciarse en televisión abierta?”, octubre 22, pp. 68-77.

FuenZALIDA, Valerio (1992) “¿Qué ven los campesinos chilenos en la telenovela?: Del reconocimiento a la reivindicación del televidente”, en G. Orozco Gómez 
(coord.), Miradas latinoamericanas a la televisión. México: Universidad Iberoamericana, pp. 131-162.

GonzÁlez, J. A. (1994) Más(+) cultura(s): ensayos sobre realidades plurales. México: Consejo Nacional para la Cultura y las Artes.

GonZÁlez, J. (comp.) (1998) La cofradía de las emociones (in)terminables: Miradas sobre telenovelas en México. Guadalajara: Universidad de Guadalajara.

Huerta, C. (1999) “Es tv juguete favorito...”, El Norte, septiembre 25, p. A2.

Huerta Wong, J. E. (2000) Hacia una evaluación de la televisión mexicana: Diversidad en la programación abierta durante 1999, tesis de maestría, Tecnológico de Monterrey, Monterrey.

, y A. Cerda Cristerna (2001) ¿Qué y cómo se ve televisión en México? Oferta y consumo en tres áreas metropolitanas, ponencia presentada en la III Bienal Iberoamericana de Comunicación: Globalización, tecnología y culturas, Cholula, Puebla, noviembre 8-10.

LiNDLOF, T. R. (1995) Qualitative communication research methods. Thousand Oaks, California: Sage.

Llano, Clara (1992) "Usos sociales de la televisión y de la telenovela: La telenovela en el barrio popular", en Jesús Martín-Barbero, y Sonia Muñoz (coords.), Televisión y melodrama. Colombia: Tercer Mundo Editores, pp. 215-231.

Lozano, J. C., y F. C. Martínez (2000) Consumo y lecturas negociadas de noticieros televisivos en Monterrey, Guadalajara y México, DF, ponencia presentada en el Congreso Anual 2000 de la International Communication Association (ICA), "ICA: 50 years of research in communication, culture, and cognition”, Acapulco, Guerrero.

LuLl, James (1988a) "The family and television in world cultures", en J. Lull (ed.), World families watch television. Newbury Park: Sage, pp. 237-259.

(1988b) "Constructing rituals of extension through family television viewing”, en J. Lull (ed.), World families watch television. Newbury Park: Sage, pp. 270-288. 
(1992) "Recepción televisiva, reforma y resistencia en China", en G. Orozco Gómez (coord.), Miradas latinoamericanas a la televisión. México: Universidad Iberoamericana, pp. 75-96.

Morley, D. (1992) Television, audiences, and cultural studies. Londres: Routledge.

MuÑoz, Sonia (1992) "Mundos de vida y modos de ver", en Jesús Martín-Barbero, y Sonia Muñoz (coords.), Televisión y melodrama. Colombia: Tercer Mundo Editores, pp. 233-297.

El Norte (2001) "Séptima entrega de consumo cultural" [página electrónica]. Disponible el 3 de julio de 2001 en: http://www.elnorte.com/offline/animaciones/cultura/medios/inicio.htm

Orozco Gómez, Guillermo (1992) "Familia, televisión y educación en México: La 'teoría educativa' de la madre como mediación en la recepción televisiva de los niños", en G. Orozco Gómez (coord.), Miradas latinoamericanas a la televisión. México: Universidad Iberoamericana, pp. 11-32.

RogGe, Jan-Uwe, y Klaus Jensen (1988) "Everyday life and television in West Germany: An empathic-interpretive perspective on the family as a system", en J. Lull (ed.), World families watch television. Newbury Park: Sage, pp. 80-115.

TAYLOR, S. J., y R. Bogdan (1987) Introducción a los métodos cualitativos: la búsqueda de significados. México: Paidós.

YARTO WonG, M. C. (1999) Modos de ver televisión y preferencias programáticas de mujeres de Monterrey, Guadalajara y México (manuscrito). 